\title{
Effects of 8-week Pilates training program on hamstring/ quadriceps ratio and trunk strength in adolescent baseball players: a pilot case study
}

\author{
Jae Ho Park', Hee-jae Kim ${ }^{1,2}$, Dong Hun Choi', Sok Park', Yoon Young Hwang ${ }^{3, *}$ \\ ${ }^{1}$ Institute of Sports Medicine \& Nutrition, Kwangwoon University, Seoul, Korea \\ ${ }^{2}$ Institute of Sports Science, Seoul National University, Seoul, Korea \\ ${ }^{3}$ Exercise Biochemistry Lab, Korea National Sport University, Seoul, Korea
}

The purpose of this pilot case study is to investigate the effects of Pilates training on hamstring/quadriceps ratio, trunk strength, shoulder strength, and body composition in adolescent baseball players. Eight adolescent baseball players, 15 years of age, participated in Pilates program (supervised training, 50 min per session for three times a week for 8 weeks) using reformer and Cadillac. The intensity of the program was progressively increased by applying beginner level for 1-2 weeks, intermediate level for 3-6 weeks, and advance level for 7-8 weeks. To verify the effect of the Pilates program on hamstring/quadriceps ratio, trunk strength, shoulder strength and body composition, participants performed bioelectrical impedance analysis and isokinetic testing at pre- and posttraining. After the Pilates training, there were significant increases in body weight $(P<0.01)$, left arm muscle mass $(P<0.01)$, and trunk muscle mass $(P<0.01)$. In addition, there were significant increases in left and right knee flexion peak torque $(P<0.01$ and $P<0.05$, respectively), right knee extension peak torque $(P<0.05)$, left and right hamstring/quadriceps ratio (both $P<0.01$ ), trunk flexion peak torque $(P<0.05)$ and shoulder flexion peak torque $(P<0.05)$ after 8 weeks of training. Therefore, Pilates training increased muscle mass, hamstring/ quadriceps ratio, trunk and shoulder strength, suggesting that it may help baseball players do better performance and prevent future injuries in adolescent players.

Keywords: Pilates, Baseball player, Hamstring/quadriceps ratio, Trunk strength

\section{INTRODUCTION}

Hamstring strain is one of the most common muscle injuries in various sports (Brooks et al., 2006; Lee et al., 2018). In the case of baseball, hamstring strain is the most common injuries in both collegiate and professional levels, and $25 \%$ of players injured hamstring had been sidelined for 1 month or longer (Ahmad et al., 2014; Dick et al., 2007). Furthermore, recurrence rate of hamstring strains has been announced to be $20 \%$ in major league baseball players (Ahmad et al., 2014). There are many risk factors leading to future hamstring strain. These include reduced hamstring strength (Opar et al., 2015) and lower hamstring to quadriceps strength ratio (H/Q ratio) (Lee et al., 2018). Especially, H/

Q ratio imbalance lowering than 0.6 can be a risk factor for athlete's noncontact leg injuries which happen during the closed kinetic movement such as base running in baseball (Kim and Hong, 2011). Therefore, maintaining adequate hamstring to quadriceps strength balance could be one of the most important factors to prevent injuries related to baseball.

In baseball, trunk muscle strength is needed to maximize pitcher's performance. Pitching is a total body activity requiring continuous movements involving the trunk as well as upper and lower limbs (English and Howe, 2007). It means that trunk plays a role to transfer energy from the lower limb to the upper limb for baseball players to make accurate pitch at fast speed (Solomito et al., 2015). Also, trunk muscle strength is significantly associated

${ }^{\star}$ Corresponding author: Yoon Young Hwang (D) https://orcid.org/0000-0001-7185-110X Exercise Biochemistry Lab, Korea National Sport University, 1239 Yangjae-daero, Songpa-gu, Seoul 05541, Korea

E-mail: jets520@naver.com

Received: December 1, 2019 / Accepted: December 26, 2019

This is an Open Access article distributed under the terms of the Creative Commons Attribution Non-Commercial License (https://creativecommons.org/licenses/by-nc/4.0/) which permits unrestricted non-commercial use, distribution, and reproduction in any medium, provided the original work is properly cited. 
with athletic performance factors such as sprint, agility, and jump (Prieske et al., 2015, 2016), and these are essential abilities to baseball fielders and hitters. Moreover, trunk muscle strength is also important to prevent injuries of upper extremities. Exhibiting excessive contralateral trunk tilt (CLT) during pitching has been related to faster ball speed, however this type of movement puts a strain on the shoulder and elbow joints in adolescent baseball pitchers (Oyama et al., 2013). Deficit in trunk muscle strength has been reported to be one of the most important cause of demonstrating excessive CLT (Solomito et al., 2015). Taken together, enhancing trunk strength could help baseball players do better performance and prevent future injuries.

There are several exercise methods to improve risk factors for athletic injuries. One of them is Pilates which was created in the 1920s by Joseph Pilates (Latey, 2001). It focuses on enhancing strength, flexibility, core stability, control of trunk and pelvic segments, posture and breathing (Kliziene et al., 2017; Wells et al., 2012). Because of these benefits, it has become popular with patients who suffer from chronic low back pain. It has been reported that there were significant beneficial effects of regular Pilates training on low back pain intensity by activating the deep muscles to stabilize the lumbar-pelvic region (Rydeard et al., 2006) and increasing isometric trunk extension and flexion strength (Kliziene et al., 2017). Considering the effects of trunk muscle strength on baseball performance and injury prevention explained above, it is likely that Pilates training could have beneficial effects on baseball players.

Many studies have reported that $\mathrm{H} / \mathrm{Q}$ ratio in well-trained athletes has been improved through various exercise methods such as traditional resistance training (Ibis et al., 2018), stretching (Lima et al., 2018), and nordic hamstring curl (Mjølsnes et al., 2004). Also, there was a study that trunk strength has been improved through bodyweight core training (Prieske et al., 2016). However, to the best of our knowledge, there are few studies using Pilates as an exercise program in baseball players on risk factors for athletic injuries such as H/Q ratio and trunk strength. English and Howe (2007) reported the case study on effects of Pilates training on trunk strength by measuring a double leg lowering test (DLLT). DLLT is one of the most popular methods to evaluate trunk strength for its simplicity, but there has been a problem in terms of its validity. Ladeira et al. (2005) reported that DLLT may be a useful method to evaluate spine stability, but it is not suitable for estimating trunk strength because of its low validity. Therefore, further studies are needed to investigate the effects of Pilates training on athletic performance related factors via more valid methods like isokinetic testing for assessing muscle strength.

The purpose of this pilot case study is to investigate whether 8-week Pilates training program in adolescent baseball players has beneficial effects on $\mathrm{H} / \mathrm{Q}$ ratio, trunk strength, shoulder strength, and body composition. We expect the preliminary results to provide relevant information for designing further research and facilitating planning of the Pilates training program to athletes.

\section{MATERIALS AND METHODS}

\section{Subjects}

Eight subjects were openly recruited from a convenience sample of adolescent baseball players. All of them were middle school players (ages 15 years) in Seoul, Korea. All players provided written informed consent after explanation of the study and exercise program. The study protocol was approved by the Institutional Review Board (IRB) Committee of the Korea National Sport University (IRB No. 20181214-085). The anthropometric characteristics of the subjects are shown in Table 1.

\section{Procedures}

One week prior to the baseline measurements, the subjects visited the laboratory for familiarization with a pretest. They were required to avoid performing any vigorous physical activity $24 \mathrm{hr}$ prior to the study. Also, they were recommended to get enough sleep. To investigate the effects of the 8-week Pilates training on $\mathrm{H} / \mathrm{Q}$ ratio, trunk strength, shoulder strength, and body composition, isokinetic testing and bioelectrical impedance analysis were performed. All subjects participated in Pilates program during the 8-week training period.

\section{Pilates training program}

Pilates training program using equipment such as reformer and

Table 1. Participant demographics

\begin{tabular}{|c|c|c|c|c|c|c|c|}
\hline \multirow{2}{*}{ Participant } & \multirow{2}{*}{ Sex } & \multirow{2}{*}{$\begin{array}{l}\text { Age } \\
\text { (yr) }\end{array}$} & \multirow{2}{*}{$\begin{array}{l}\text { Weight } \\
(\mathrm{kg})\end{array}$} & \multirow{2}{*}{$\begin{array}{l}\text { Height } \\
(\mathrm{cm})\end{array}$} & \multirow{2}{*}{$\begin{array}{c}\mathrm{BMl} \\
\left(\mathrm{kg} / \mathrm{m}^{2}\right)\end{array}$} & \multicolumn{2}{|c|}{$\mathrm{H} / \mathrm{Q}$ ratio } \\
\hline & & & & & & Left & Right \\
\hline 1 & Male & 15 & 67.5 & 180.2 & 20.8 & 0.40 & 0.43 \\
\hline 2 & Male & 15 & 60.2 & 167.7 & 21.4 & 0.55 & 0.50 \\
\hline 3 & Male & 15 & 59.5 & 172.6 & 20.0 & 0.67 & 0.70 \\
\hline 4 & Male & 15 & 76.0 & 173.6 & 25.2 & 0.49 & 0.51 \\
\hline 5 & Male & 15 & 86.4 & 178.0 & 27.3 & 0.42 & 0.39 \\
\hline 6 & Male & 15 & 59.9 & 177.3 & 19.1 & 0.53 & 0.50 \\
\hline 7 & Male & 15 & 72.8 & 172.5 & 24.5 & 0.45 & 0.42 \\
\hline 8 & Male & 15 & 55.3 & 169.0 & 19.4 & 0.59 & 0.57 \\
\hline
\end{tabular}

$\mathrm{BMI}$, body mass index; $\mathrm{H} / \mathrm{O}$ ratio, hamstring to quadriceps strength ratio. 
Cadillac is shown in Table 2. During the 8-week intervention period, all subjects participated in the supervised training program for 50 min per session for 3 times a week under an instruction of Pilates expert and a supervision of an exercise physiologist. The program consists of three phases: (a) warm-up ( $5 \mathrm{~min}$ ), (b) main exercise ( $40 \mathrm{~min}$ ), and (c) cool-down ( $5 \mathrm{~min}$ ). The intensity of the program was progressively increased by applying beginner level

\section{Table 2. Pilates training program}

\begin{tabular}{|c|c|}
\hline Program level & Contents \\
\hline \multirow[t]{4}{*}{ Warm up (5 min) } & 1. Breathing \\
\hline & 2. Hip release \\
\hline & 3. Roll-up preparation \\
\hline & 4. Arm circles \\
\hline \multicolumn{2}{|c|}{ Main exercise (40 min) } \\
\hline \multirow[t]{7}{*}{ 1-2 Weeks } & 1. Single leg stretch \\
\hline & 2. Double leg stretch \\
\hline & 3. Rolling like a ball \\
\hline & 4. Swimming (modification) \\
\hline & 5. Obliques \\
\hline & 6. Spine twist \\
\hline & 7. Spine stretch forward \\
\hline \multirow[t]{7}{*}{ 3-4 Weeks } & 1. Roll up \\
\hline & 2. Rolling like a ball \\
\hline & 3. Side bend \\
\hline & 4. Spine stretch forward \\
\hline & 5. Side leg series \\
\hline & 6. Criss cross \\
\hline & 7. Mermaid (modification) \\
\hline \multirow[t]{8}{*}{ 5-6 Weeks } & 1. The hundred \\
\hline & 2. Single leg circles \\
\hline & 3. Leg pull back \\
\hline & 4. Leg pull front \\
\hline & 5. Roll over \\
\hline & 6. Side bend \\
\hline & 7. Spine stretch forward \\
\hline & 8. Side leg series \\
\hline \multirow[t]{7}{*}{ 7-8 Weeks } & 1. The hundred \\
\hline & 2. Side kick: front/back \\
\hline & 3. Side kick: small circles \\
\hline & 4. Rowing \\
\hline & 5. Swan \\
\hline & 6. Teaser \\
\hline & 7. Side bend \\
\hline \multirow[t]{4}{*}{ Cool down (5 min) } & 1. Head nods \\
\hline & 2. Hip rolls \\
\hline & 3. Breast stroke prep \\
\hline & 4. Cat stretch \\
\hline
\end{tabular}

for 1-2 weeks, intermediate level for 3-6 weeks, and advance level for 7-8 weeks to participants (Table 2).

\section{Outcome measures}

\section{Anthropometric measures}

Anthropometric data included body weight ( $\mathrm{kg}$ ), body mass index $\left(\mathrm{kg} / \mathrm{m}^{2}\right)$, and muscle mass $(\mathrm{kg})$ were measured using bioelectrical impedance analysis (InBody 720, Biospace, Seoul, Korea). Body weight and height presented to the nearest $0.1 \mathrm{~kg}$ and 0.1 $\mathrm{cm}$, respectively.

\section{Isokinetic testing}

The knee extension and flexion peak torque (PT) of each leg, trunk extension and flexion PT, and shoulder extension and flexion PT of dominant side were concentrically measured at $240 \%$ sec (15 repetitions) using Humac NORM isokinetic dynamometers (CSMi, Stoughton, MA, USA). PT is recorded in Newton-meters (Nm). All subjects had prior exposures (2-3 testing) on the isokinetic dynamometers to familiarize them to the machine and the testing procedures.

\section{Data analysis}

Since the sample size is too small $(n=8)$, our quantitative data is presented individually. Data were analyzed using mean change scores, with Cohen effect sizes (ES) and associated confidence limits applied to quantify magnitude of change. Data were presented as means \pm standard deviations. We also applied a paired $t$-test to indicate the statistical meaning of the change by using IBM SPSS Statistics ver. 25.0 (IBM Co., Armonk, NY, USA). Statistical significance was set at $P<0.05$. We recognize that using the statistical analysis have limited meaning in this context, and we do not intend to deduce athlete populations from our outcomes.

\section{RESULTS}

\section{Body composition}

Fig. 1 demonstrates the individual responses on body composition variables between pre- and posttraining. Mean body weight was increased by $2.99 \pm 2.04 \mathrm{~kg}(P<0.01 ; \mathrm{ES}, 1.46)$. Mean left arm muscle mass was increased by $0.22 \pm 0.64 \mathrm{~kg}(P<0.01$; ES, $1.31)$, and also mean trunk muscle mass by $1.17 \pm 0.68 \mathrm{~kg}(P<$ 0.01; ES, 1.73). Other variables (muscle mass of right arm, left and right leg) tended to increase after training, but were not statistically significant. 

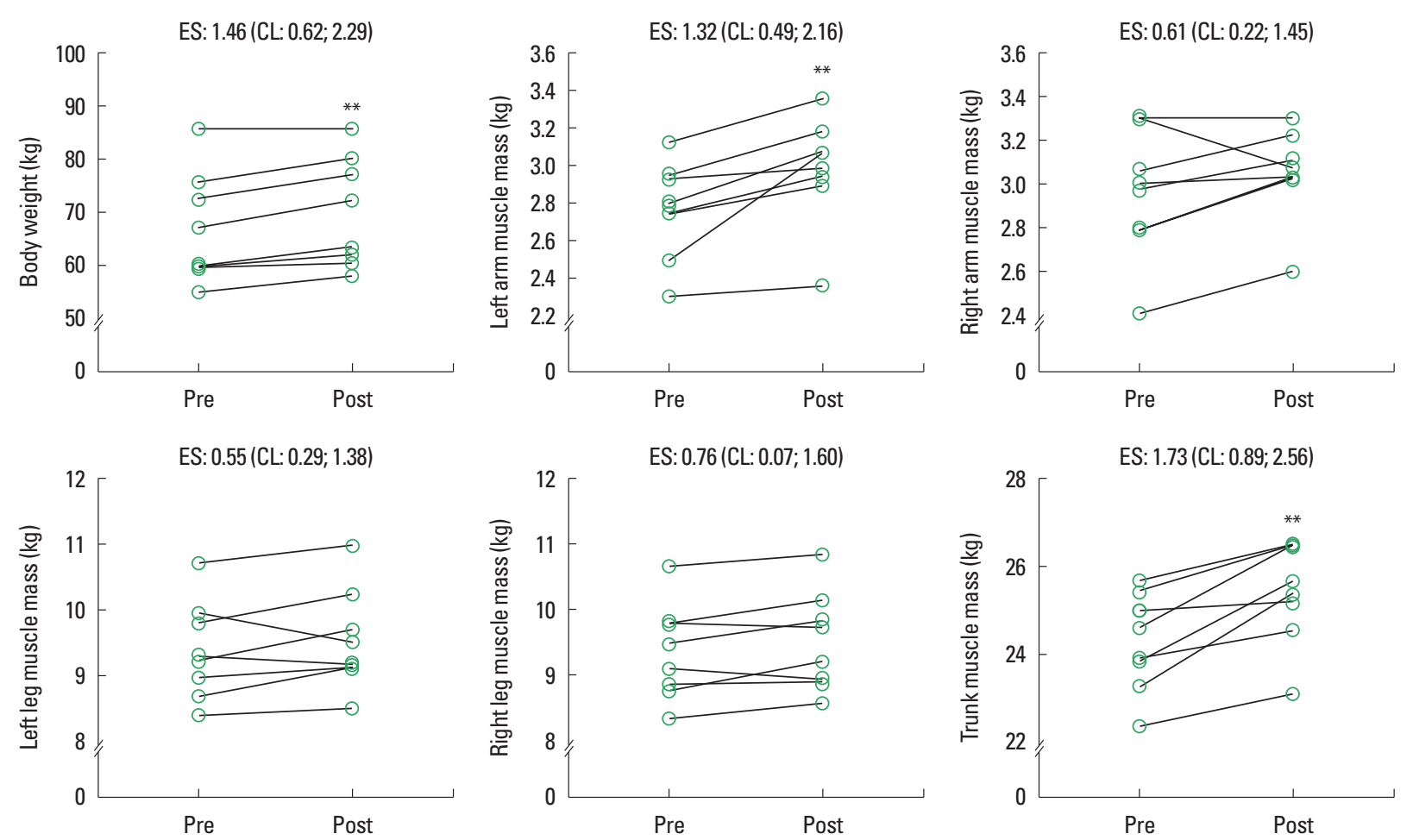

Fig. 1. Individual responses and effect sizes of weight, left and right arm muscle mass, left and right leg muscle mass, and trunk muscle mass between pre- and posttraining. ES, effect size; CL, confidence limits. ES were interpreted as $\leq 0.2$ small, 0.5 moderate, $\geq 0.8$ large. ${ }^{* *} P<0.01$.
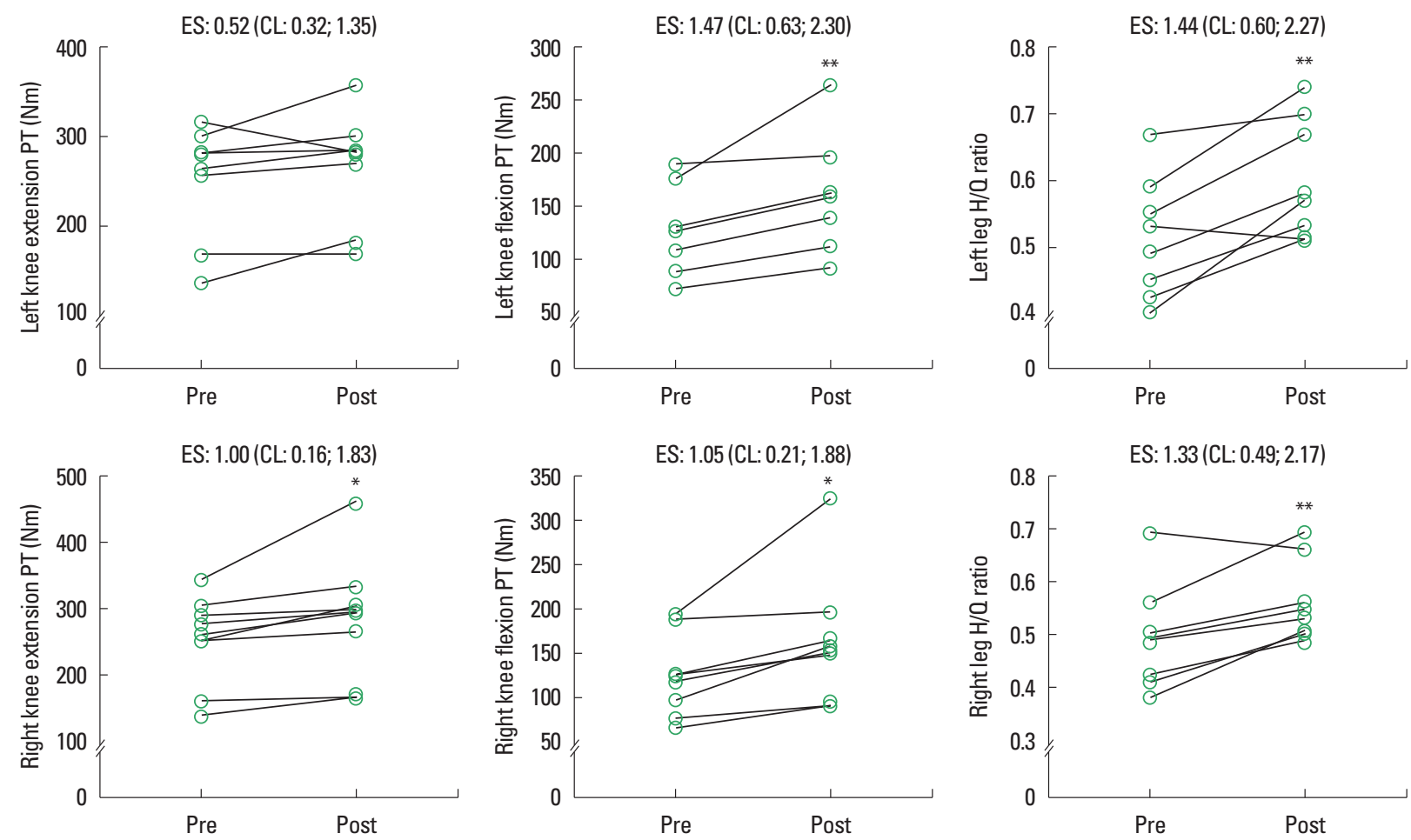

Fig. 2. Individual responses and effect sizes of left and right knee extension peak torque, left and right knee flexion peak torque, and left and right knee hamstring to quadriceps strength ratio between pre- and posttraining. ES, effect size; $\mathrm{CL}$, confidence limits; Nm, newton meter; $\mathrm{H} / \mathrm{O}$ ratio, hamstring to quadriceps strength ratio; PT, peak torque. ES were interpreted as $\leq 0.2$ small, 0.5 moderate, $\geq 0.8$ large. ${ }^{*} P<0.05$. ${ }^{* *} P<0.01$. 

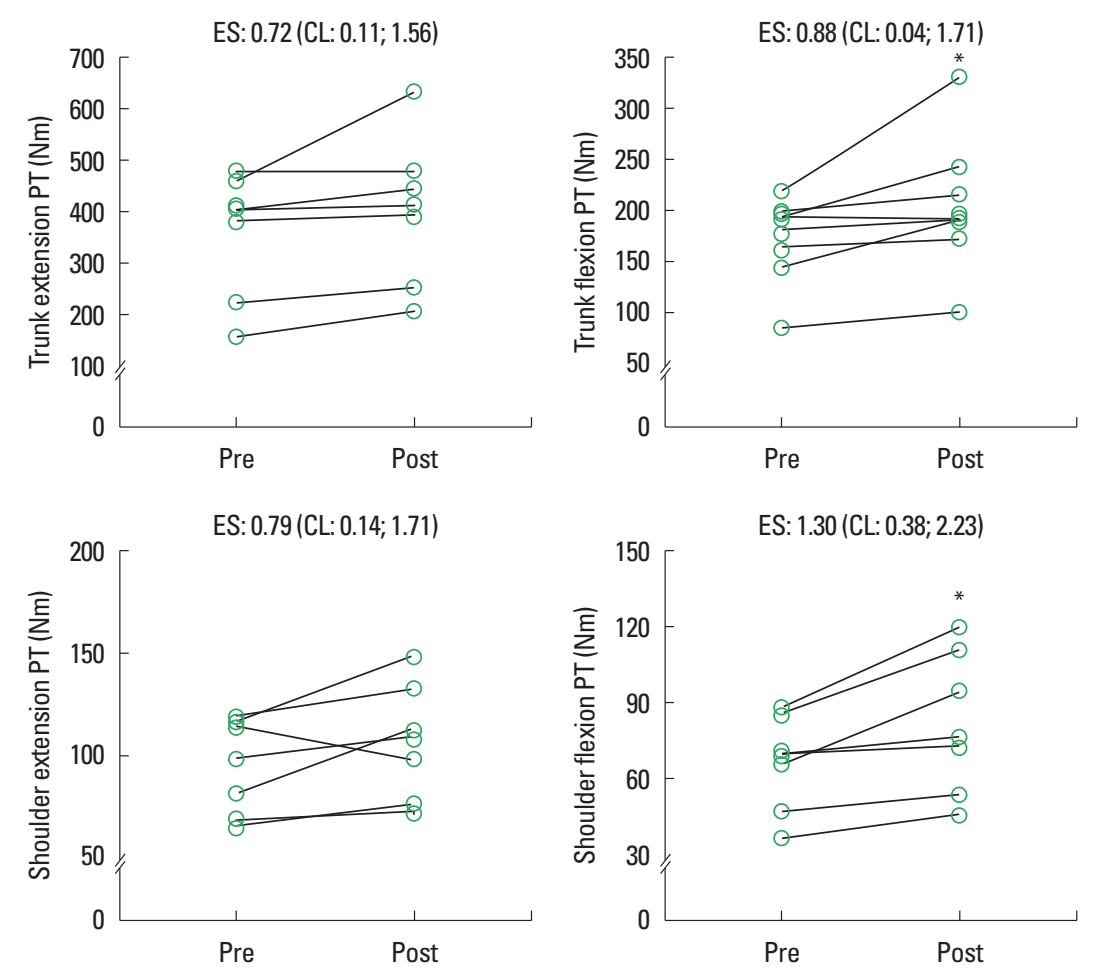

Fig. 3. Individual responses and effect sizes of trunk extension and flexion peak torque, and shoulder extension and flexion peak torque between pre- and posttraining. ES, effect size; CL, confidence limits; $\mathrm{Nm}$, newton meter; PT, peak torque. ES were interpreted as $\leq 0.2$ small, 0.5 moderate, $\geq 0.8$ large. ${ }^{*} P<0.05$.

\section{Isokinetic strength of knee}

Fig. 2 demonstrates the individual responses on muscle strength of knee between pre- and posttraining. Mean left and right knee flexion PT was increased by $33.74 \pm 23 \mathrm{Nm}(P<0.01$; ES, 1.47) and $41.13 \pm 39.3 \mathrm{Nm}(P<0.05 ; \mathrm{ES}, 1.05)$, respectively. Mean right knee extension PT was increased by $35.81 \pm 35.87 \mathrm{Nm}(P<0.05$; ES, 1.00), and mean left knee extension PT tended to be increased by $14.81 \pm 28.59 \mathrm{Nm}(P=0.19 ; \mathrm{ES}, 0.52)$. Mean left and right leg $\mathrm{H} / \mathrm{Q}$ ratio was increased by $0.09 \pm 0.06(P<0.01 ; \mathrm{ES}, 1.44)$ and $0.07 \pm 0.05(P<0.01 ; \mathrm{ES}, 1.33)$, respectively.

\section{Isokinetic strength of trunk}

Fig. 3 demonstrates the individual responses on muscle strength of trunk between pre- and posttraining. Mean trunk flexion PT was increased by $31.65 \pm 36.09 \mathrm{Nm}(P<0.05 ; \mathrm{ES}, 0.88)$, and mean trunk extension PT tended to be increased by $41.34 \pm 57.18 \mathrm{Nm}$ $(P=0.08 ; \mathrm{ES}, 0.72)$.

\section{Isokinetic strength of shoulder}

Fig. 3 demonstrates the individual responses on muscle strength of shoulder of dominant side between pre- and posttraining. Mean shoulder flexion PT was increased by $15.56 \pm 11.96 \mathrm{Nm}(P<0.05$; ES, 1.30), and mean shoulder extension PT tended to be increased by $12.75 \pm 16.22 \mathrm{Nm}(P=0.08$; ES, 0.79$)$.

\section{DISCUSSION}

To our knowledge, this is the first study to investigate whether 8-week Pilates training using reformer and Cadillac in adolescent baseball players has beneficial effects on H/Q ratio, trunk and shoulder strength, and body composition. The key findings of this pilot case study were that subjects were able to increase the muscle mass, H/Q ratio, trunk and shoulder strength via 8-week Pilates training program.

There were significant increases in left arm and trunk muscle mass between pre- and posttraining. This indicates that the Pilates training may have a beneficial effect on muscle mass in adolescent baseball players. Hoffman et al. (2009) compared anthropometric and performance variables in professional baseball players. According to them, the players playing in major league team had significantly higher muscle mass than the players playing in minor league team, even if they were all professional level. Also, muscle mass was significantly correlated to baseball performance such as total bases, home runs, and slugging percentage (Hoffman et al., 2009). Taken together, increasing muscle mass could be an important factor for adolescent baseball players. However, most research on Pilates have studied the effects on body composition in nonthletic subjects such as sedentary adults (Vaquero-Cristóbal et al., 2015, 2016) or patients with nonspecific low back pain 
(Lopes et al., 2017). While Lopes et al. (2017) did not compare muscle mass between pre- and posttraining program, significant increases were observed for muscle mass after 16 weeks of reformer Pilates program (Vaquero-Cristóbal et al., 2016) as well as 16 weeks of mat Pilates program (Vaquero-Cristóbal et al., 2015). Meanwhile, there were studies of Pilates training in healthy subjects such as baseball players (English and Howe, 2007) and female dancers (Ahearn et al., 2018), but they did not measure muscle mass related variables. Taken together, to the best of our knowledge, this is the first study to report that Pilates training significantly increased muscle mass in adolescent baseball players.

There were also significant increases in trunk and shoulder flexion strength between pre- and posttraining. According to the review paper, increasing muscular strength can enhance athletic performance and decrease the risk of athletic injuries (Suchomel et al., 2016). Especially, trunk muscle strength is significantly associated with athletic performance factors like sprint, agility, and jump (Prieske et al., 2015, 2016), and these are essential for baseball fielders and hitters playing competitively. Moreover, trunk muscle strength is needed to maximize pitch speed via transferring energy from the lower limb to the upper limb (Solomito et al., 2015). Therefore, increasing trunk muscle strength could be essential for adolescent baseball players. It has been reported that significant beneficial effects of Pilates training on isometric trunk extension and flexion strength in patients with chronic low back pain (Kliziene et al., 2017). However, these results cannot be generalized to all athletes. In another study, there were significant increases in trunk strength in baseball player after 10-week Pilates training (English and Howe, 2007). They measured trunk strength by using DLLT, however this method has been criticized for its low validity (Ladeira et al., 2005). As an isokinetic testing is considered the gold standard for measuring dynamic muscle function and strength (Duarte et al., 2018), we additionally investigated the effects of Pilates training on trunk strength by using this method. As a result, trunk flexion PT was significantly increased, and trunk extension PT also tended to be increased after 8 weeks Pilates training in adolescent baseball players.

$\mathrm{H} / \mathrm{Q}$ ratio imbalance lowering than 0.6 may be a risk factor for athlete's noncontact leg injuries which can happen during the closed kinetic movement such as base running in baseball (Kim and Hong, 2011). So, it is one of the most important factors to maintain adequate $\mathrm{H} / \mathrm{Q}$ ratio balance for preventing injuries in baseball players. Unexpectedly, seven out of eight participants in our study had low left and right $\mathrm{H} / \mathrm{Q}$ ratio at pretraining $(0.51 \pm$ 0.09 and $0.50 \pm 0.10$, respectively). After the Pilates training, mean left $\mathrm{H} / \mathrm{Q}$ ratio was increased by $0.09 \pm 0.06(P<0.01 ; \mathrm{ES}, 1.44)$, and mean right $\mathrm{H} / \mathrm{Q}$ ratio by $0.07 \pm 0.05(P<0.01 ; \mathrm{ES}, 1.33)$. It is remarkable that left $\mathrm{H} / \mathrm{Q}$ ratio changed to normal range $(0.60 \pm$ $0.09)$ and right $\mathrm{H} / \mathrm{Q}$ ratio changed close to normal range $(0.57 \pm$ $0.07)$ after the Pilates training. Especially, the results are important in that they were accompanied by an increase in both knee extension and flexion strength concurrently. To the best of our knowledge, there are no data on the effects of Pilates training on H/Q ratio in baseball player. Although it was not the case of baseball players, it was reported that the H/Q ratio decreased with age, and particularly the ratio decreased sharply between 11 and 12 years old (0.82 to 0.65$)$ in high-level youth football players (Peek et al., 2018). While it is hard to generalize their findings to baseball players directly, it is clear that early detection of an imbalance $\mathrm{H} / \mathrm{Q}$ ratio is important to avoid future hamstring injuries in adolescent players. Taken together, Pilates program could be a proper alternative to prevent an imbalance in $\mathrm{H} / \mathrm{Q}$ ratio.

Our study has several limitations. First, as this study was a pilot case study including only treatment group, we cannot ensure that the results were totally due to the Pilates training. Thus, further studies should include control groups to investigate the interaction effects. Second, as we could not control team training and personal nutrition of each athlete, we cannot assure the results were completely attributable to our Pilates training program. Therefore, further studies tracking daily training volume and food intake of each athlete which might have occurred during the intervention period are needed to establish the effects of Pilates training.

In summary, the purpose of this pilot case study is to investigate whether 8 weeks Pilates training in adolescent baseball players has beneficial effects on $\mathrm{H} / \mathrm{Q}$ ratio, trunk and shoulder strength, and body composition. The results from this study suggest that Pilates training may contribute to increase muscle mass, $\mathrm{H} / \mathrm{Q}$ ratio, trunk and shoulder strength. Taken together, our results suggest that Pilates training may help baseball players do better performance and prevent future injuries in adolescent players.

\section{CONFLICT OF INTEREST}

No potential conflict of interest relevant to this article was reported.

\section{ACKNOWLEDGMENTS}

This work was supported by the Ministry of Education of the Republic of Korea and the National Research Foundation of Ko- 
rea (NRF-2018S1A5B5A07072918).

\section{REFERENCES}

Ahearn EL, Greene A, Lasner A. Some effects of supplemental pilates training on the posture, strength, and flexibility of dancers 17 to 22 years of age. J Dance Med Sci 2018;22:192-202.

Ahmad CS, Dick RW, Snell E, Kenney ND, Curriero FC, Pollack K, Albright JP, Mandelbaum BR. Major and minor league baseball hamstring injuries: epidemiologic findings from the major league baseball injury surveillance system. Am J Sports Med 2014;42:1464-1470.

Brooks JH, Fuller CW, Kemp SP, Reddin DB. Incidence, risk, and prevention of hamstring muscle injuries in professional rugby union. Am J Sports Med 2006;34:1297-1306.

Dick R, Sauers EL, Agel J, Keuter G, Marshall SW, McCarty K, McFarland E. Descriptive epidemiology of collegiate men's baseball injuries: National Collegiate Athletic Association Injury Surveillance System, 19881989 through 2003-2004. J Athl Train 2007;42:183-193.

Duarte JP, Valente-Dos-Santos J, Coelho-E-Silva MJ, Couto P, Costa D, Martinho D, Seabra A, Cyrino ES, Conde J, Rosado J, Gonçalves RS. Reproducibility of isokinetic strength assessment of knee muscle actions in adult athletes: Torques and antagonist-agonist ratios derived at the same angle position. PLoS One 2018;13:e0202261.

English T, Howe K. The effect of pilates exercise on trunk and postural stability and throwing velocity in college baseball pitchers: single subject design. N Am J Sports Phys Ther 2007;2:8-21.

Hoffman JR, Vazquez J, Pichardo N, Tenenbaum G. Anthropometric and performance comparisons in professional baseball players. J Strength Cond Res 2009;23:2173-2178.

Ibis S, Aktuğ ZB, Iri R. Does individual-specific strength training have an effect upon knee muscle strength balances? Knee muscle strength balances. J Musculoskelet Neuronal Interact 2018;18:183-190.

Kim D, Hong J. Hamstring to quadriceps strength ratio and noncontact leg injuries: a prospective study during one season. Isokinet Exerc Sci 2011;19:1-6

Kliziene I, Sipaviciene S, Vilkiene J, Astrauskiene A, Cibulskas G, Klizas S, Cizauskas G. Effects of a 16-week Pilates exercises training program for isometric trunk extension and flexion strength. J Bodyw Mov Ther 2017;21:124-132

Ladeira CE, Hess LW, Galin BM, Fradera S, Harkness MA. Validation of an abdominal muscle strength test with dynamometry. J Strength Cond Res 2005;19:925-930.

Latey P. The Pilates method: history and philosophy. J Bodyw Mov Ther 2001;5:275-282.

Lee JWY, Mok KM, Chan HCK, Yung PSH, Chan KM. Eccentric hamstring strength deficit and poor hamstring-to-quadriceps ratio are risk factors for hamstring strain injury in football: a prospective study of 146 professional players. J Sci Med Sport 2018;21:789-793.

Lima CD, Brown LE, Ruas CV, Behm DG. Effects of static versus ballistic stretching on hamstring: quadriceps strength ratio and jump performance in ballet dancers and resistance trained women. J Dance Med Sci 2018;22:160-167.

Lopes S, Correia C, Félix G, Lopes M, Cruz A, Ribeiro F. Immediate effects of Pilates based therapeutic exercise on postural control of young individuals with non-specific low back pain: a randomized controlled trial. Complement Ther Med 2017;34:104-110.

Mjølsnes R, Arnason A, Østhagen T, Raastad T, Bahr R. A 10-week randomized trial comparing eccentric vs. concentric hamstring strength training in well-trained soccer players. Scand J Med Sci Sports 2004; 14:311-317.

Opar DA, Williams MD, Timmins RG, Hickey J, Duhig SJ, Shield AJ. Eccentric hamstring strength and hamstring injury risk in Australian footballers. Med Sci Sports Exerc 2015;47:857-865.

Oyama S, Yu B, Blackburn JT, Padua DA, Li L, Myers JB. Effect of excessive contralateral trunk tilt on pitching biomechanics and performance in high school baseball pitchers. Am J Sports Med 2013;41:2430-2438.

Peek K, Gatherer D, Bennett KJM, Fransen J, Watsford M. Muscle strength characteristics of the hamstrings and quadriceps in players from a high-level youth football (soccer) Academy. Res Sports Med 2018;26: 276-288.

Prieske O, Muehlbauer T, Borde R, Gube M, Bruhn S, Behm DG, Granacher U. Neuromuscular and athletic performance following core strength training in elite youth soccer: role of instability. Scand J Med Sci Sports 2016;26:48-56.

Prieske O, Muehlbauer T, Krueger T, Kibele A, Behm DG, Granacher U. Role of the trunk during drop jumps on stable and unstable surfaces. Eur J Appl Physiol 2015;115:139-146.

Rydeard R, Leger A, Smith D. Pilates-based therapeutic exercise: effect on subjects with nonspecific chronic low back pain and functional disability: a randomized controlled trial. J Orthop Sports Phys Ther 2006;36: 472-484.

Solomito MJ, Garibay EJ, Woods JR, Õunpuu S, Nissen CW. Lateral trunk lean in pitchers affects both ball velocity and upper extremity joint moments. Am J Sports Med 2015;43:1235-1240.

Suchomel TJ, Nimphius S, Stone MH. The importance of muscular strength in athletic performance. Sports Med 2016;46:1419-1449.

Vaquero-Cristóbal R, Alacid F, Esparza-Ros F, López-Plaza D, Muyor JM, López-Miñarro PA. The effects of a reformer Pilates program on body composition and morphological characteristics in active women after a detraining period. Women Health 2016;56:784-806. 
Vaquero-Cristóbal R, Alacid F, Esparza-Ros F, Muyor JM, López-Miñarro PÁ. The effects of 16-weeks pilates mat program on anthropometric variables and body composition in active adult women after a short detraining period. Nutr Hosp 2015;31:1738-1747.

Wells C, Kolt GS, Bialocerkowski A. Defining Pilates exercise: a systematic review. Complement Ther Med 2012;20:253-262. 